\title{
Organosilicon Reagents in Natural Product Synthesis
}

\section{Hari Prasad}

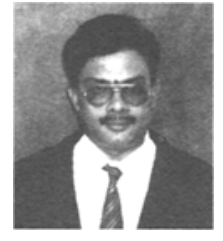

Hari Prasad S teaches post graduate students medicinal organic chemistry and organic spectroscopy at the Chemistry Department, Central College, Bangalore University, Bangalore. His research includes synthetic and mechanistic organic chemistry.

\section{Keywords}

Organosilicon reagents, prostaglandins, hormones, drugs, terpenoids.
Berzelius, the Swedish chemist in 1807 introduced the term 'organic compounds' as those substances derived from once living organisms (organized systems). Carbon exhibits the property of catenation (formation of chains) and forms a plethora of compounds on earth. Silicon on the other hand which is placed below carbon in the periodic table does not exhibit this property. This article is a brief account of some of the several reagents and classes of compounds encountered in organosilicon chemistry.

\section{Introduction}

Silicon is the second most abundant element on the surface of the earth, after oxygen. It is the mildest of metals. Silicon does not occur free in nature, but is found as silica (quartz, sand) or as silicates (feldspar, kaolinite), etc. In the periodic table, it belongs to group 14, and is placed below carbon. It has atomic number 14 and comprises three isotopes 28 (92.18\%), 29 (4.17\%) and $30(3.11 \%)$. Industrially, silicon is prepared by the carbon reduction of silica in an electric arc furnace.

$$
\mathrm{SiO}_{2}+2 \mathrm{C} \longrightarrow \mathrm{Si}+2 \mathrm{CO}
$$

Silicon is purified by the zone melting method of refining.

\section{Organosilicon Based Reagents}

Organosilicon compounds do not occur free in nature, and are prepared synthetically. The property of catenation (formation of alkanes, alkenes, alkynes, etc.) observed in carbon chemistry is absent in silicon chemistry. This is because of the high affinity of silicon towards oxygen. The silicon-oxygen $\sigma$ bond strength is $368 \mathrm{kJmol}^{-1}$, whereas the silicon-silicon $\sigma$ bond strength is $230 \mathrm{kJmol}^{-1}$ (Table 1). 


\begin{tabular}{|lllllllll|}
\hline X & H-X & C-X & O-X & F-X & Cl-X & Br-X & I-X & Si-X \\
C & 416 & 356 & 336 & 485 & 321 & 285 & 213 & 290 \\
Si & 323 & 290 & 368 & 582 & 391 & 310 & 234 & 230 \\
\hline
\end{tabular}

Thus, in the oxygen rich atmosphere of the earth, the silicon analogues similar to carbon do not occur. Instead, silicon bonds with oxygen and other metals to form a variety of mineral silicates.

The first halosilane-silicon tetrachloride was discovered by Berzelius (Box 1), by reacting elemental chlorine with silica and coke, in the same year he discovered silicon.

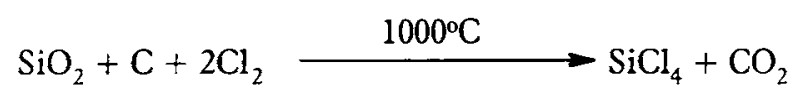

Friedel and Craft in 1863 reacted silicon tetrachloride with Franklands diethyl zinc to isolate the first organosilicon compound: tetraethylsilane.

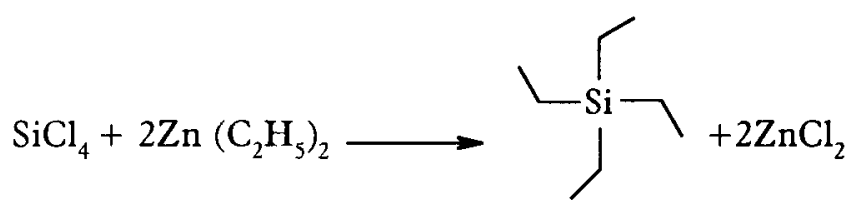

Today, all the organosilicon reagents are manufactured by two separate processes.

Direct process: Elemental silicon is reacted with chlorinated hydrocarbons in presence of a metal catalyst to form organohalosilanes.

$\mathrm{Si}+2 \mathrm{CH}_{3} \mathrm{Cl} \underset{300^{\circ} \mathrm{C}}{\stackrel{\text { Cu cat. }}{\longrightarrow}} \mathrm{Cl}-\mathrm{Si}_{\mathrm{CH}_{3}} \mathrm{Cl}+\sim 40$ by products

Stepwise process employing Grignard reagents: Silicon tetrachloride upon systematic treatment with Grignard reagents and/or alkyl lithiums form a range of organosilicon reagents of
Table 1: Comparison of the bond strengths of carbon and silicon analogues $(\mathrm{kJ}$ $\mathrm{mor}^{-1}$ ).

Box 1. Joens J F von Berzelius (1779 - 1848)

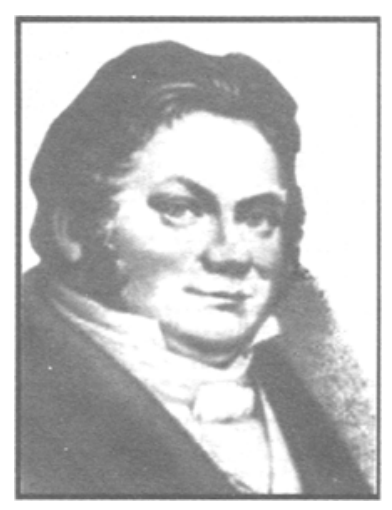

Silicon was first isolated in 1823 by Berzelius by passing metallic potassium vapours over red-hot silica to obtain a brown mass. Addition of water to the brown mass gave silicon as an amorphous solid with liberation of hydrogen gas. Berzelius also obtained silicon by the decomposition of potassium hexafluorosilicate $\left(\mathrm{K}_{2} \mathrm{SiF}_{6}\right)$ with an excess of potassium. 


\section{Box 2. Silanols and Silicones}

Halosilanes upon careful hydrolysis form silanols. The silanols being highly reactive immediately undergo condensation polymerization to form a range of commercially useful silicones. This pioneering work was carried out by Kipping, considered today as the father of classical organosilicon chemistry. The polymerization occurs till the hydroxy groups are end blocked with other protecting groups like the alkyl/ aryl group, ether/ester group or the trimethylsilyl group. The silicone polymers so obtained maybe fluids or rubbers. Silicone fluid polymers are water repellant (due to the organic side groups) and heat stable. They are used as lubricants, polishes, paints, varnishes, in water-proofing textiles, in glassware, and antifoaming agents. Silicone rubbers retain their elasticity and are used as electrical gaskets and insulators.

Table 2. Stepwise process for the preparation of organosilicon reagents.

high synthetic utility (Table 2 ). In both the processes, a mixture of compounds is obtained which are separated by careful fractionation.

\section{The Nature of the Carbon-silicon Bond: Bond}

\section{Polarization}

Silicon is more electropositive than carbon. This results in the

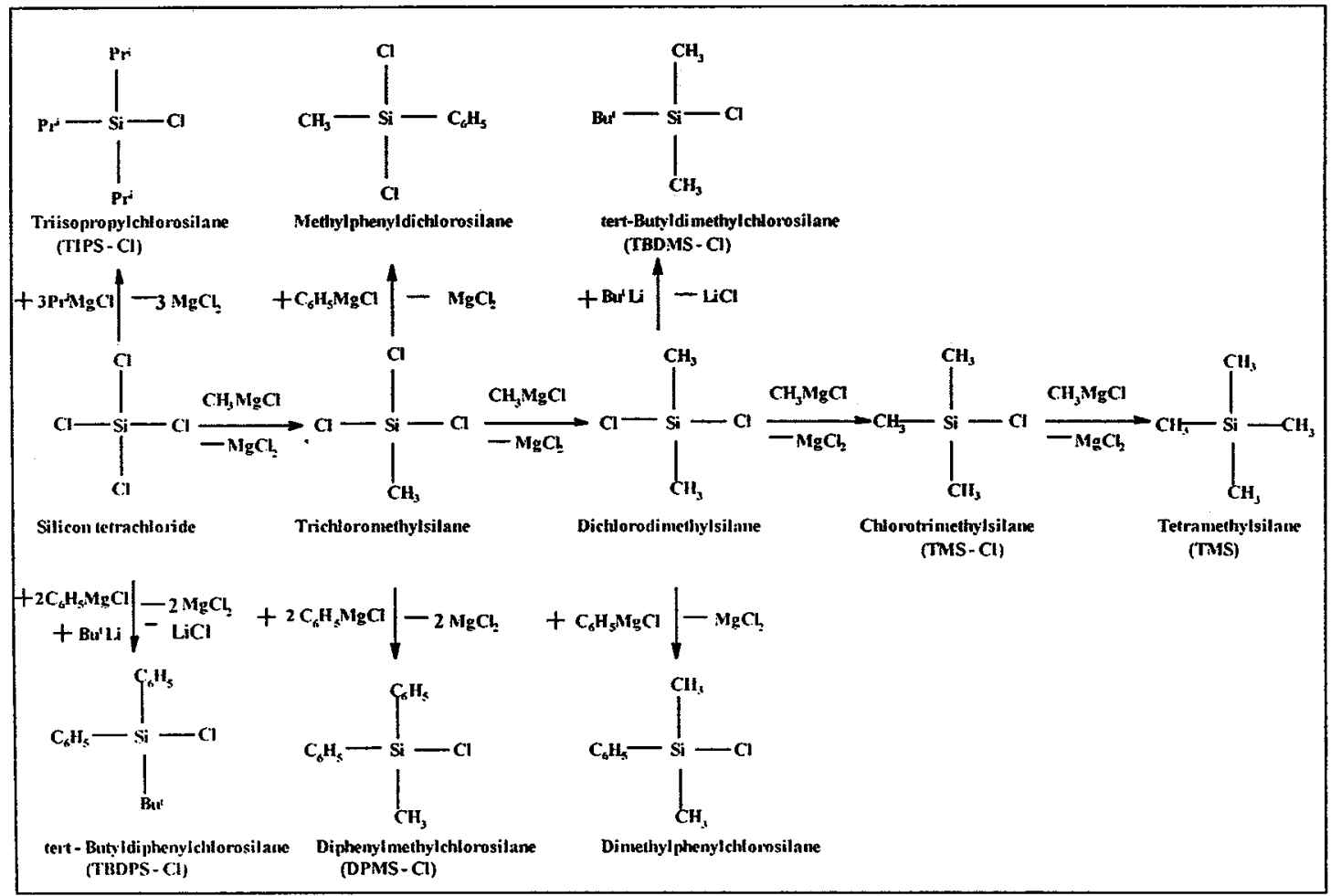


strongly polarized carbon-silicon bond as:

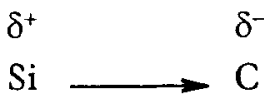

Due to the strong bond polarization, nucleophilic attack on silicon leads to bond heterolysis. The cleavage is especially facile when the attacking nucleophile is oxygen or a halogen. This property of bond heterolysis is used for desilylation reactions, rendering silicon to be used as a protecting group/masking agent in organic synthesis.
Much of organo-

silicon chemistry is

driven by the formation of strong silicon-oxygen or silicon-fluorine bonds at the expense of other weaker bonds.<smiles>[R][Si]([R])([R])N[Si]([R])([R])N[C-]C</smiles>

The larger carbon-silicon bond affords less steric hindrance than the carbon-carbon bond. Thus, when silicon is bonded to carbon, it is considered to be a 'super-proton'. This is because it reacts in a manner similar to a proton. On the other hand, when silicon is bonded to oxygen, it behaves as an enfeebled proton.

\section{The $\alpha$-silyl and $\beta$-silyl Effects}

All known organosilicon chemistry is based on the mechanistic pathways involving the valence ' $p$ ' and empty ' $d$ ' orbitals of silicon. The metallation of a tetraalkylsilane leads to the formation of a carbanion $\alpha$ - to the silyl group. Such carbanions $\alpha$ - to the silyl group are extremely stable. The ease of formation and stabilization of $\alpha$-carbanions to silicon have been attributed to delocalization of the extra electron density centered in the $2 p$ orbital on carbon into an empty $3 d$ orbital on silicon.

Silicon also stabilizes a carbocation $\beta$ to the silicon. The stabilisation is due to the $(\sigma \rightarrow p)_{\pi}$ conjugation from the carbonsilicon bond to the vacant $p$ orbital of the $\beta$-carbocation.

Most of organosilicon chemistry may be explained based on the above properties of silicon.

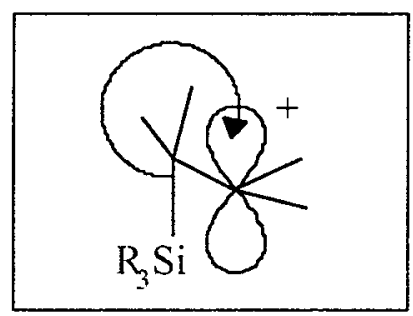

The $\beta$-silyl effect. 


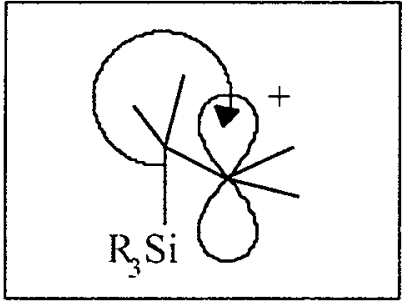

The $\beta$-silyl effect.

\section{Synthesis and Utility of Organosilicon Compounds}

Many different classes of organosilicon compounds are known. Discussed herein is a brief preparation of some of the classes and their utility in the synthesis of some natural products/drugs of commercial importance. Several individual methods are reported for the synthesis of each of these classes. The most important general reaction however, for the formation of an organosilicon compound remains the reaction of a suitable anion with a halosilane.

Silyl ethers: Reactive hydroxy/thiol or carboxylic groups (protic substrates) are protected using organosilicon reagent in presence of a suitable base.

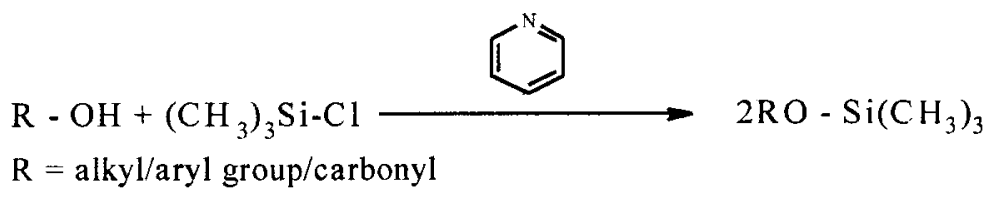

The silyl ethers so formed are stable due to the high affinity of silicon towards oxygen. This provides an opportunity to use organosilyl groups as protecting groups for protic substrates. For example, carboxylic acids due to their high polarity, cannot be analyzed by gas-liquid chromatography. However, their trimethylsilyl esters being highly volatile maybe analyzed using gas-liquid chromatography.

The deprotection of the trimethylsilyl-ether/esters to the parent compounds occur quite readily on exposure to nucleophiles such as methanol in presence of catalytic amount of acid or base.

$$
\begin{aligned}
\mathrm{R}^{\prime} \mathrm{O}-\mathrm{Si}\left(\mathrm{CH}_{3}\right)_{3} \stackrel{\mathrm{MeOH} / \mathrm{H}^{+} \text {or } \mathrm{OH}^{-}}{\longrightarrow} & \begin{array}{l}
\mathrm{R}^{\prime}-\mathrm{OH}+\left(\mathrm{CH}_{3}\right)_{3} \mathrm{Si}-\mathrm{OR} \\
\mathrm{R}=\mathrm{H} \text { or } \mathrm{Me}
\end{array}
\end{aligned}
$$

Such a reaction has been efficiently utilized in the synthesis of prostaglandin $\mathrm{E}_{2}\left(\mathrm{PGE}_{2}\right)$ methyl ester. Prostaglandin $\mathrm{F}_{2 \alpha}$ methyl ester upon treatment with trimethylsilyldiethylamine undergoes regiospecific protection of the $C_{11}$ hydroxy group. Fur- 


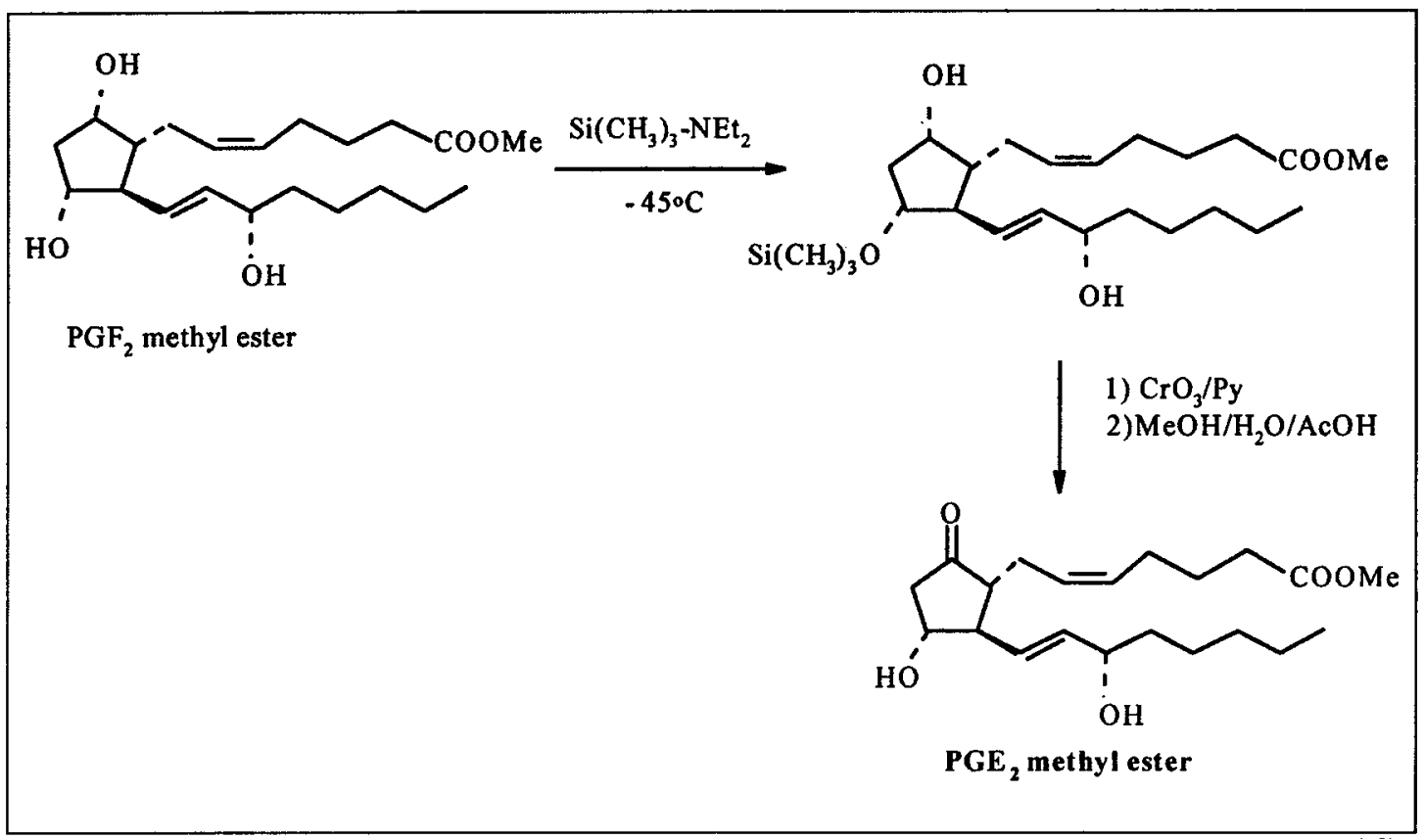

ther oxidation with chromium trioxide followed by deprotection Structure 1. in acid medium gives $\mathrm{PGE}_{2}$ methyl ester. $\mathrm{PGE}_{2}$ is the most common and biologically most potent of mammalian prostaglandins. It is oxytocic and abortifacient in nature (Structure 1).

The protection behaviour of the organosilyl group has also been utilized in the synthesis of ( $\mathrm{R}$ )-isoproterenol a drug used as an adrenergic bronchodilator. The synthesis uses two types of silicon based protecting groups, viz, the diisopropylsilyl group and the triethylsilyl group (see Structure 2).

Silyl enol ethers: These compounds are generally prepared by the trapping of enolate ions. Treatment of an enolisable carbonyl compound with base followed by quenching with chlorotrimethylsilane gives a silyl enol ether.

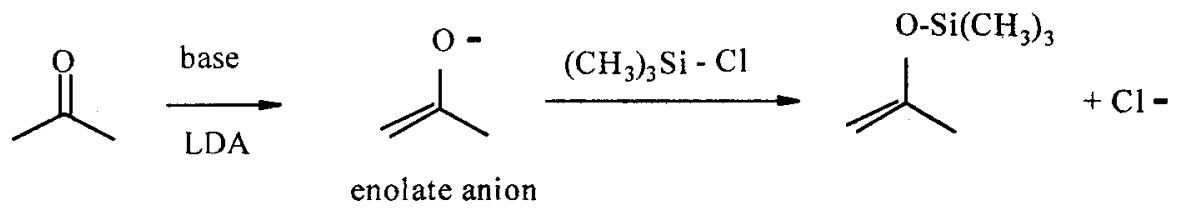


<smiles>CC(C)[Si](Br)(Br)C(C)C</smiles><smiles>Cc1cccc(C)n1</smiles><smiles>COC(CI)c1ccc2c(c1)O[Si](C(C)C)(C(C)C)O2</smiles>

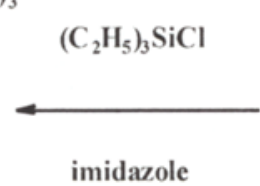<smiles>CC(C)SC1CCC1</smiles>

1)

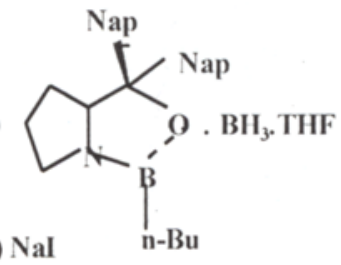

2) $\mathrm{NaI}$<smiles>COc1cc(C(O)CI)ccc1O</smiles>

$\mathrm{Pr}^{\mathrm{i}}-\mathrm{NH}_{2}$<smiles>CCO[C@@H](CNC(C)C)c1ccc2c(c1)O[Si](C(C)C)(C(C)C)O2</smiles>

$\mathrm{Tf}=$ trifluoromethane sulfonate $\mathrm{Nap}=$ naphthyl

\section{$\mathrm{KF} / \mathrm{HCl} / \mathrm{MeOH}$}

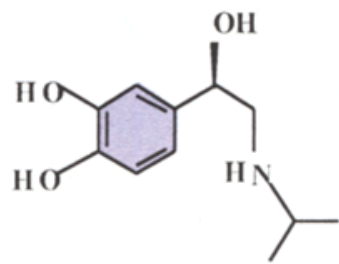

(R)-Isoproterenol
Structure 2.
The silyl enol ethers undergo reaction with strong electrophiles. The resulting carbocation is stabilized through resonance. Final desilylation with a nucleophile gives the higher carbonyl derivative.

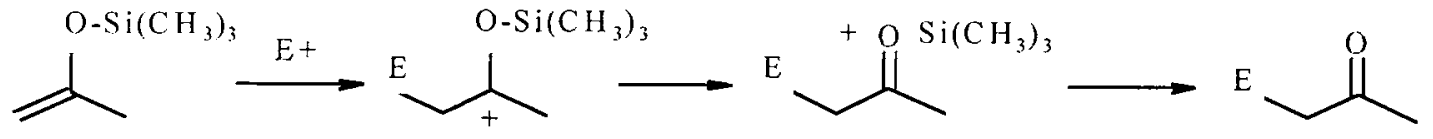


The synthesis of [6]-gingerol, the major phenol and most important of the pungent principles of ginger oil, has been achieved by utlilizing such a reaction.

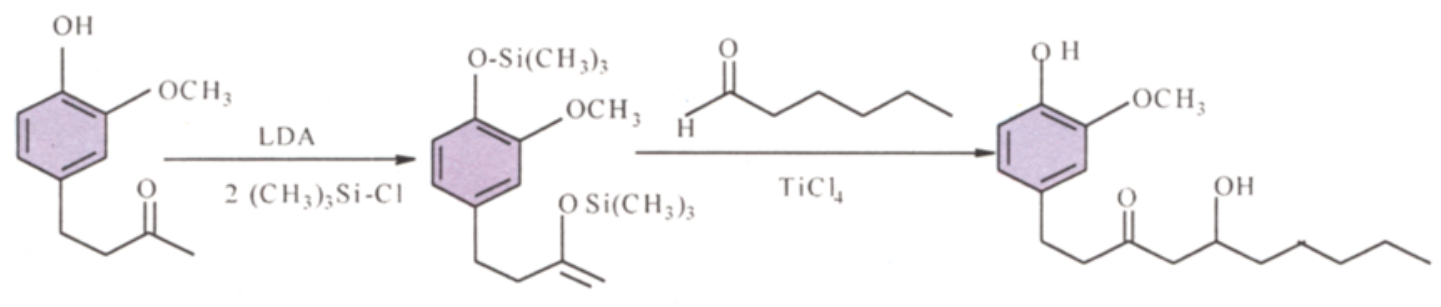

|6|-Gingerol

Other examples for the utility of silyl enol ethers in natural product synthesis is in the case of the Ireland-Claisen rearrangement to form methyl santolinate, and 11,15-deoxy$\mathrm{PGE}_{2}$ methyl ester. (TBDMS - $\mathrm{t}$-butyldimethylsilyl)
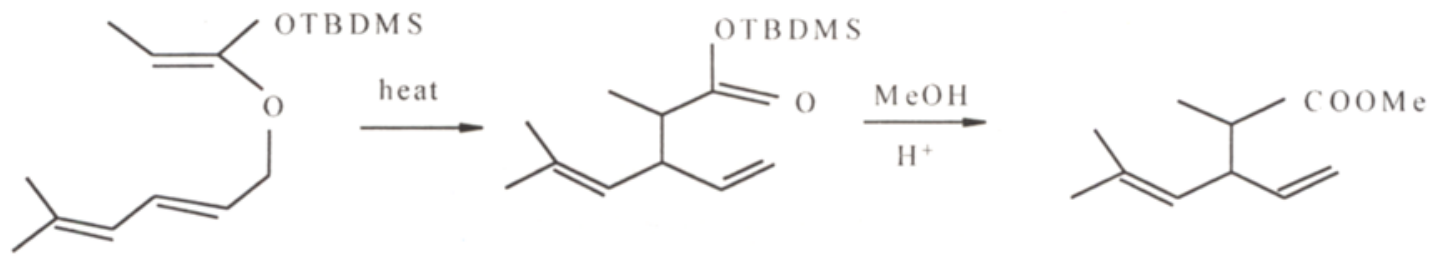

1) $\mathrm{Li} / \mathrm{NH}_{3} / \mathrm{THF}$
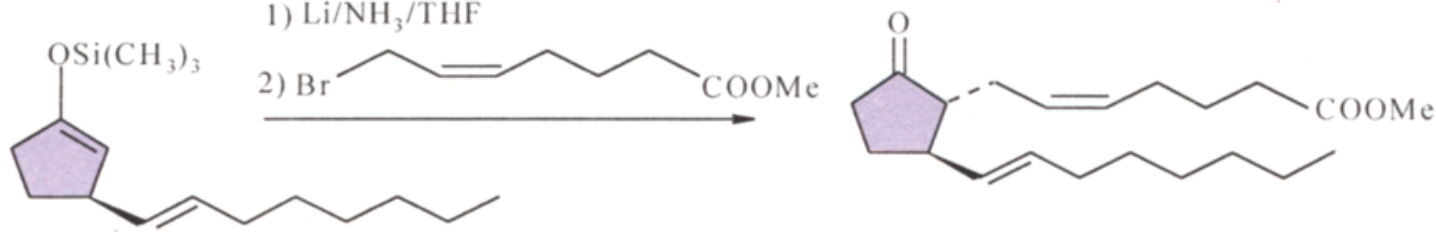

11,15-Desoxy-PGE 2 methyl ester

Alkynyl silanes: Alkynyl silanes are normally prepared by the metallation of terminal alkyne followed by quenching with a halosilane.

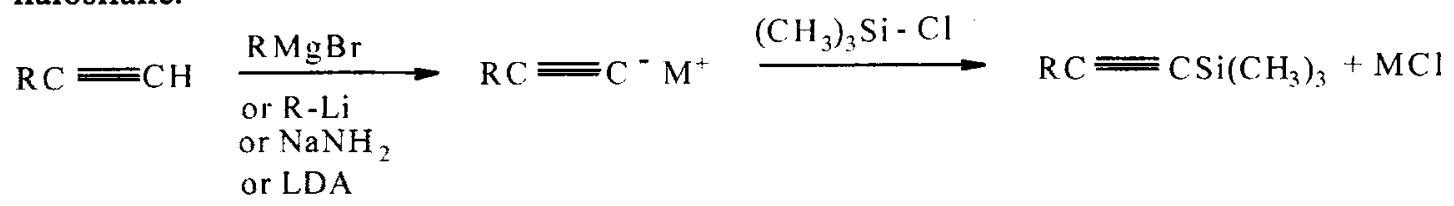

The reverse reaction (desilylation) and liberation of alkyne is achieved using a good nucleophile such as the hydroxide ion, fluoride ion, methanolysis, silver (I) followed by cyanide ion heterolysis, etc. 
An intramolecular Friedel-Crafts acylation reaction has been efficiently utilized in the synthesis of muscone. The acyl carbocation formed attacks the silicon bearing carbon leading to cyclisation. Stabilization is achieved through the $\beta$-silyl effect. Desilylation, further methylation and reduction gives muscone. Muscone, an oily macrocyclic ketone is the chief odorous constituent of musk widely used in perfumery.

$\left(\mathrm{CH}_{3}\right)_{3} \mathrm{Si}-\mathrm{C} \equiv \mathrm{C}-\left(\mathrm{CH}_{2}\right)_{12}-\stackrel{\mathrm{O}}{\|}-\mathrm{Cl} \frac{\mathrm{AlCl}_{3}}{\text { high dilution }}$<smiles>O=C1C#CCCCCCCCCCCC1</smiles>

$\underset{\mathrm{H}_{2} \text { /catalyst }}{\stackrel{\left(\mathrm{CH}_{3}\right)_{2} \mathrm{CuLi}}{\longrightarrow}}$<smiles>CCCCCCCCCCCC(=O)CC(C)CCCCCCC</smiles>

The synthesis of cecropia juvenile hormone which plays an important role in the development of the silkworm moth, is another example for the utility of an alkynyl silane. The trimethylsilyl group in this synthesis behaves as a masking agent for the acetylenic anion.

$$
\mathrm{CH}_{3} \mathrm{C} \equiv \mathrm{C} \mathrm{Si}\left(\mathrm{CH}_{3}\right)_{3} \stackrel{\mathrm{n}-\mathrm{BuLi}}{\longrightarrow} \mathrm{Li}_{-}-\mathrm{CH}_{2}-\mathrm{C} \equiv \mathrm{CSi}\left(\mathrm{CH}_{3}\right)_{3}
$$

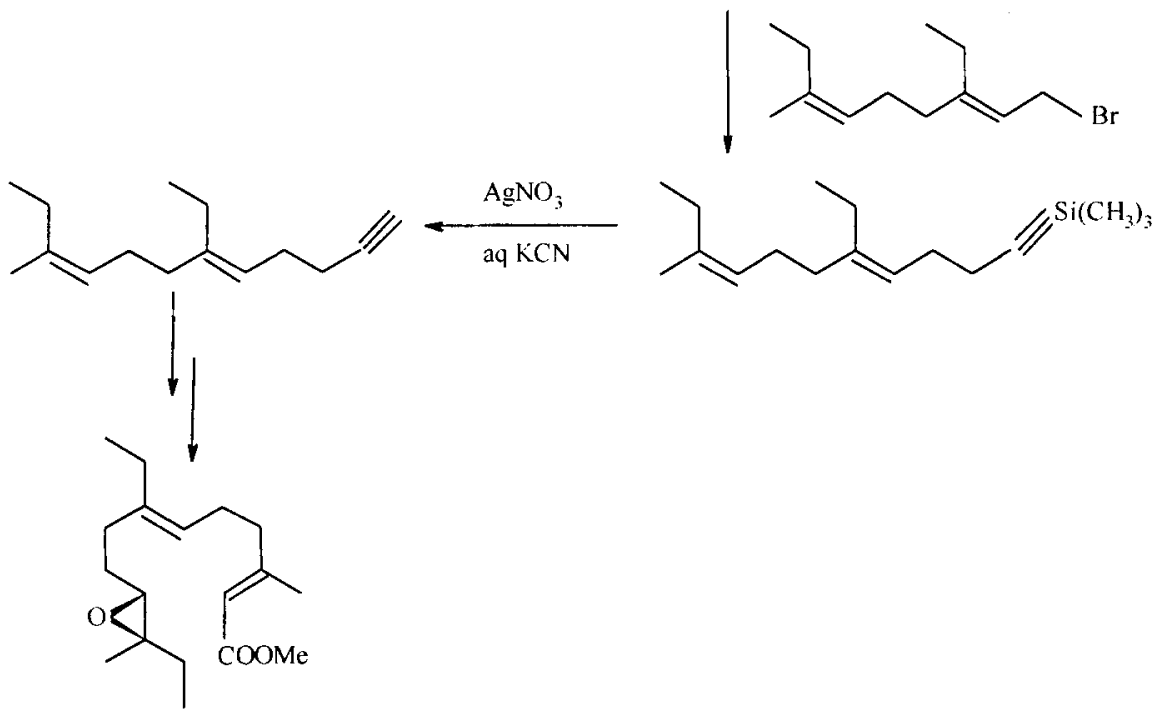

Cecropia juvenile hormone 
Vinyl Silanes: The Wurtz-Fittig coupling reaction of a vinyl halide with a metal and a halosilane (which behaves as an electrophilic quench) is one of the earliest methods for the formation of vinylsilanes.

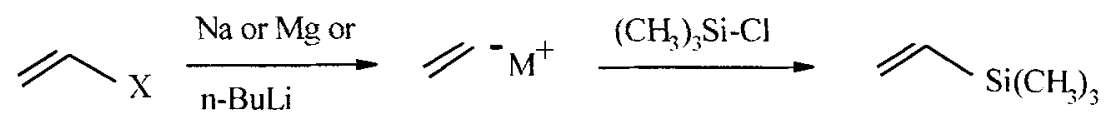

$$
\mathrm{X}=\mathrm{Br} \text { or } \mathrm{Cl}
$$

The synthetic utilities of vinylsilanes are enormous. They undergo stereospecific electrophilic substitutions at the ipso position, with the silicon stabilizing the $\beta$-carbocation. Here, the reverse reaction and conversion back to vinyl halide is feasible and vinylsilanes undergo facile halogenation at the ipso-position of silicon when treated with halogen. This renders the silicon to behave as a protecting group for the vinyl anion. The protection and halogenation reactions have been utilized for the synthesis of Z-tamoxifen, an anticancer drug for treating estrogen dependant metastatic breast cancers in humans. The synthesis of Z-tamoxifen, the active isomer which exhibits antineoplastic properties is achieved by halogenating a vinyl silane followed by conversion to Z-tamoxifen.
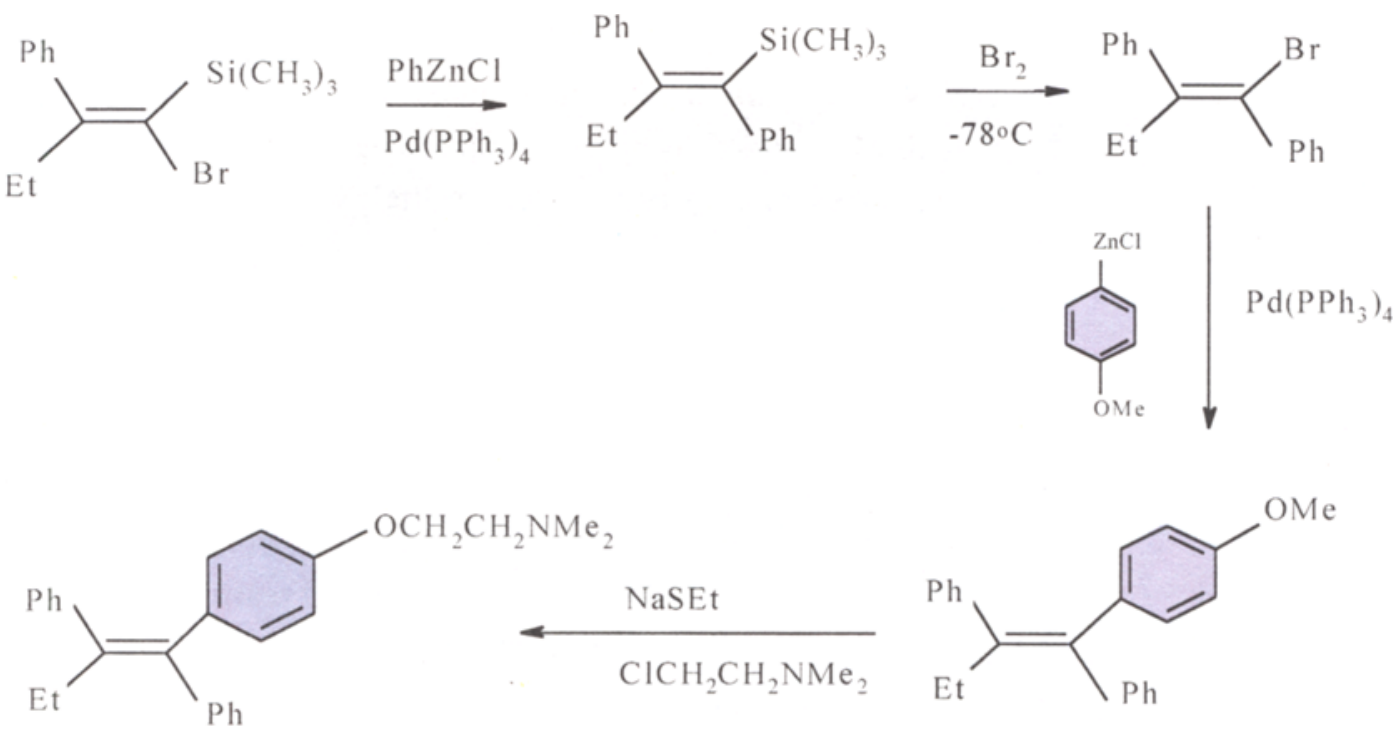

Z-Tamoxifen 
A similar halogenation and organozinc coupled reaction has also been utilized in the synthesis of yellow scale pheromone, scales being small very prolific insects having young that suck the juices of citrus plants.
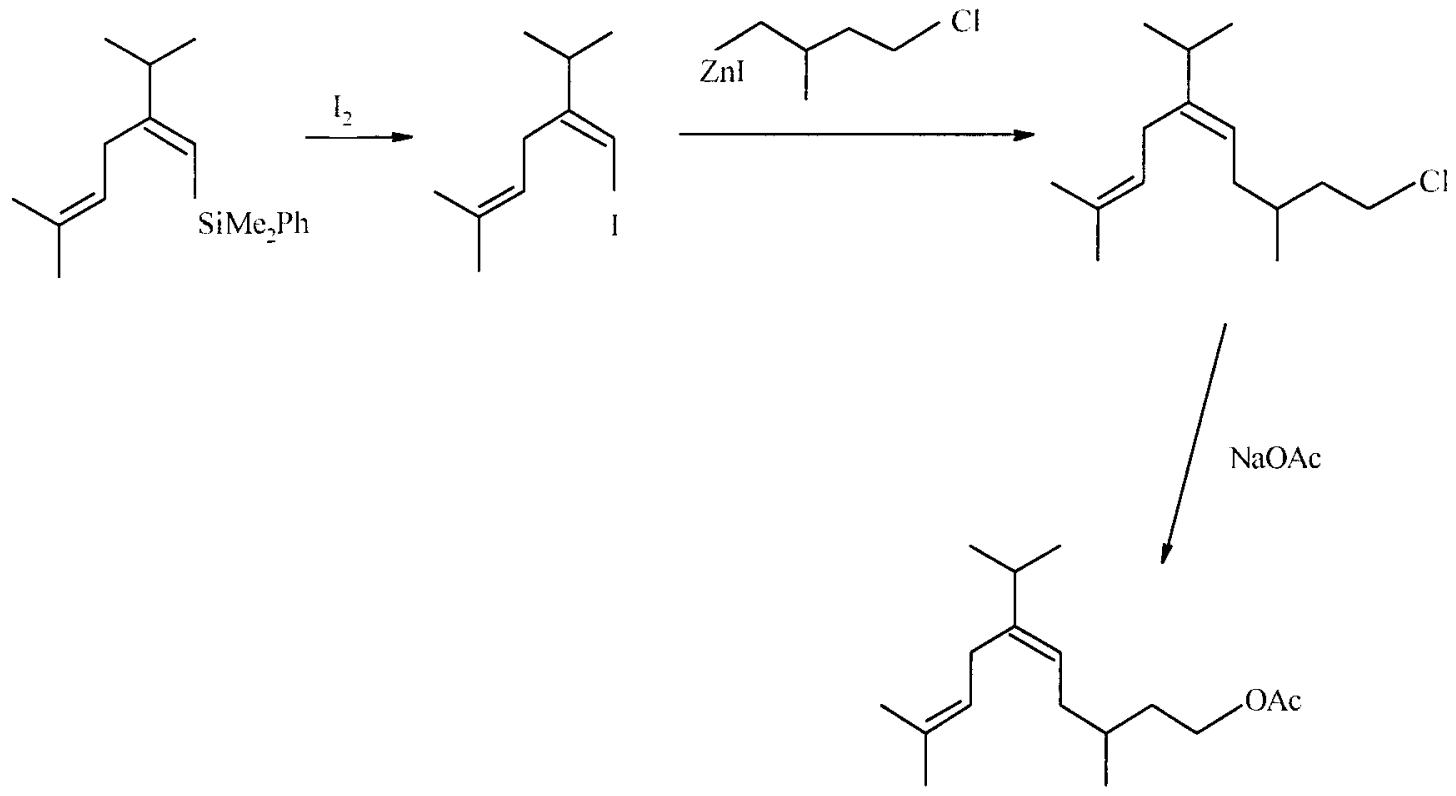

Yellow scale pheromone

$\alpha, \beta$-Epoxysilanes: Epoxidation of vinylsilanes with reagents such as meta-chloroperoxybenzoic acid ( $m$-CPBA) yields the corresponding epoxysilane in high yields.

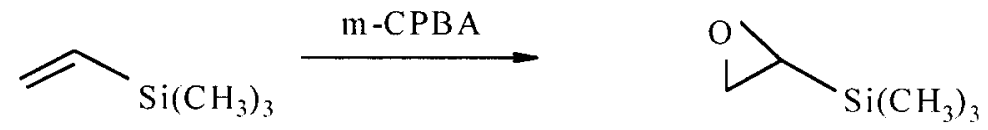

Epoxysilanes too are of high synthetic utility. One instance has been for the synthesis of exobrevicomin the active pheromone of the western pine beetle. Treatment of an $\alpha, \beta$ epoxysilane with Grignard reagent forms the regiospecific $\beta$ hydroxysilane, which upon hydrogen peroxide oxidation gives exobrevicomin. 


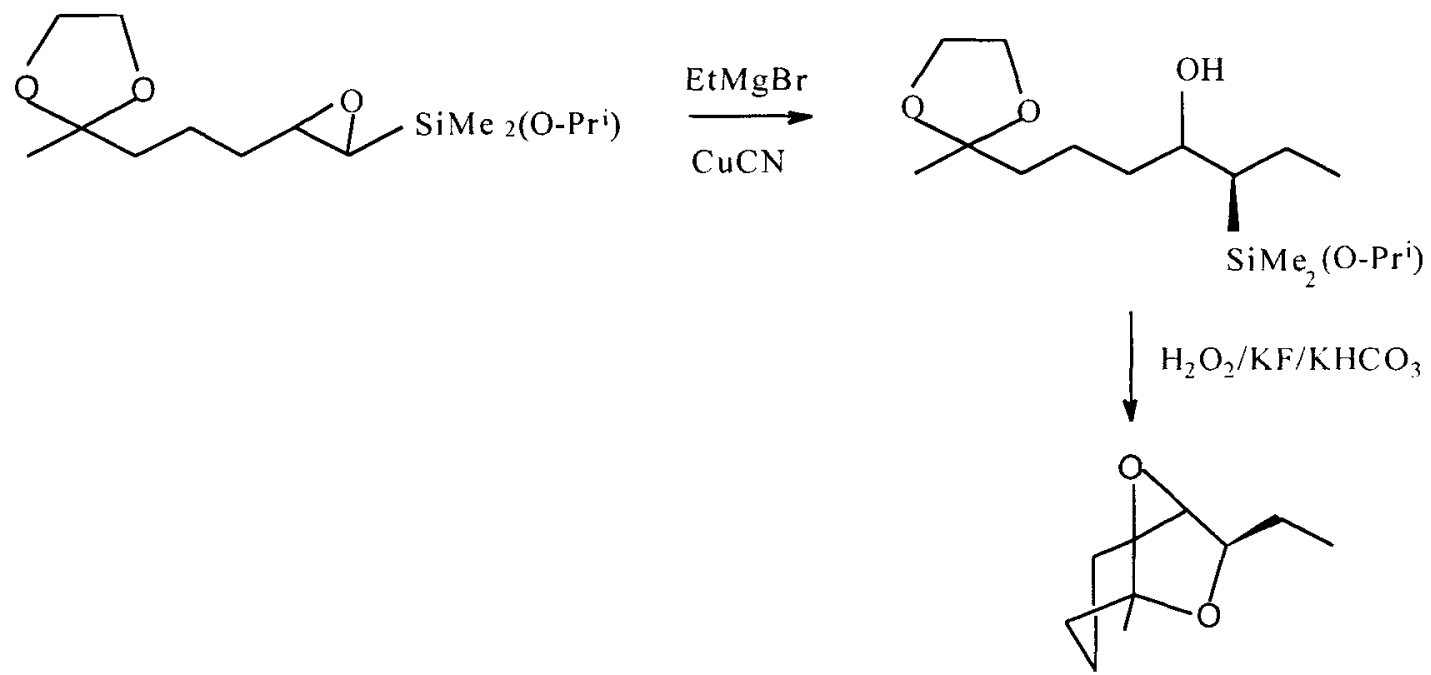

Exobrevicomin

The usefulness of $\alpha, \beta$-epoxysilanes has also been illustrated in a three step synthesis of Latia luciferin from dihydro- $\beta$-ionone.

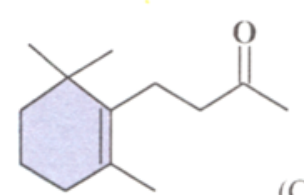

$\left(\mathrm{CH}_{3}\right)_{3} \mathrm{Si}-\mathrm{CH}-\mathrm{Cl}$

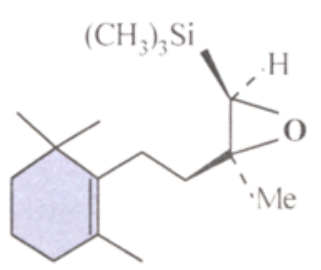

$\mathrm{HCOOH}$

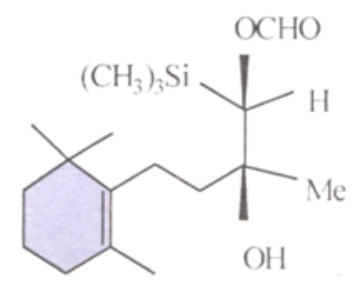

anti-elimination

$-\left(\mathrm{CH}_{3}\right)_{3} \mathrm{Si}-\mathrm{OH}$

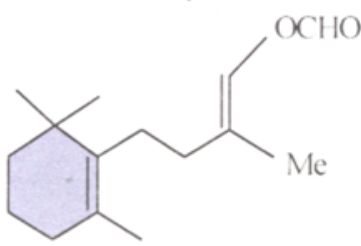

Luciferin

Luciferin is a pigment found in bioluminescent animals like the fireflies, marine crustaceans, etc.

$\beta$-Hydroxysilanes: One of the most important reactions of organosilicon chemistry is the Peterson olefination reaction 
(also called as the Silyl-Wittig reaction). Like the Wittig reaction, the Peterson olefination reaction results in the formation of alkenes. Reacting $\alpha$-silylated carbanions (stabilized through the $\alpha$-silyl effect) with carbonyl compounds yield $\beta$-hydroxysilanes. The $\beta$-hydroxysilanes undergo elimination of silanol to afford olefin.

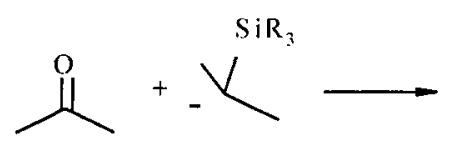<smiles>CC(C)(C)C(C)(C)[Hg][Mg]</smiles>

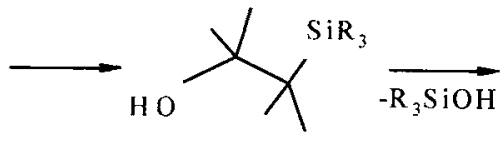<smiles>CCC(C)=C(C)C</smiles>

The Peterson olefination has been readily used for the synthesis of $\beta$-gorgonene, a non-isoprenoid sesquiterpene.
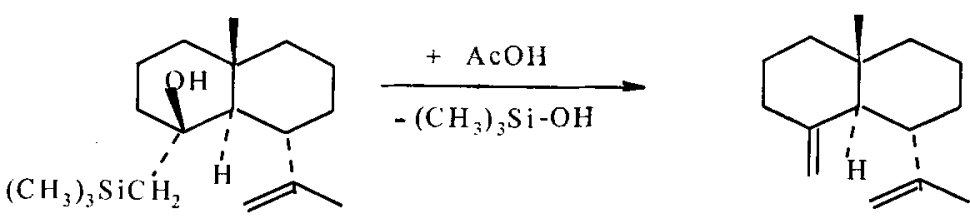

$\beta$-Gorgonene

Arylsilanes: Arylsilanes are normally prepared by quenching an aryl-metal system with a chlorosilane. The aryl-metal system may be a Grignard reagent, or sodium aryl or lithium aryl etc.
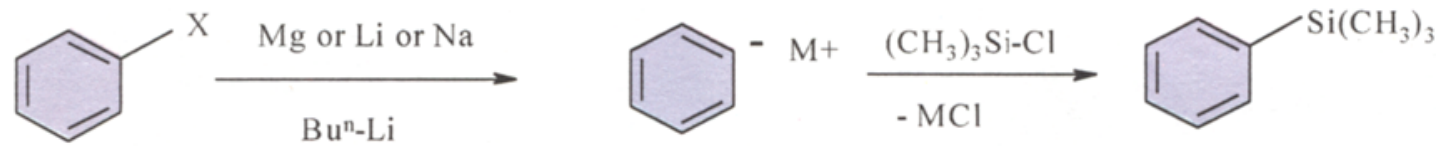

One of the most impressive one step construction of the steroid nucleus employs the co-oligomerisation of a diyne with bistrimethylsilylacetylene. The resulting steroidal aryl silane upon careful protiodesilylation with trifluoroacetic acid followed by oxidation with lead tetraacetate gives estrone the most important female sex hormone among estrogens.

Allyl silanes: Allylsilanes are the homologues of vinyl silanes. They are much more reactive than vinylsilanes, and are 


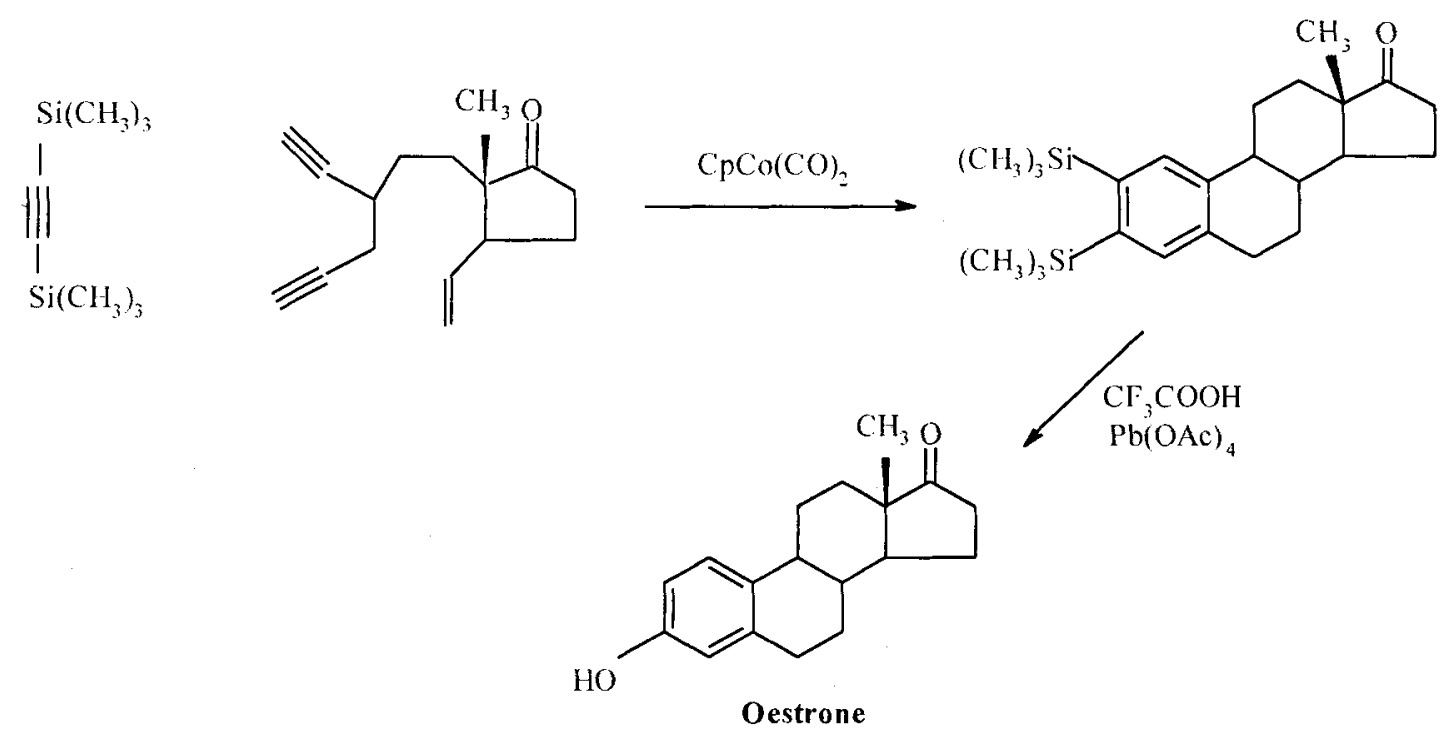

prepared by quenching allyl anions with halosilanes.

$$
\int_{\mathrm{N}}^{\mathrm{CH}_{2}-\mathrm{Cl}}+\mathrm{Na} \text { or } \mathrm{Mg} \text { or } \mathrm{Li} \longrightarrow \prod_{\mathrm{M}=\text { metal }} \mathrm{CH}_{2}^{-} \mathrm{M}^{+} \frac{\left(\mathrm{CH}_{3}\right)_{3} \mathrm{Si}-\mathrm{Cl}}{-\mathrm{MCl}} \sqrt{1} \mathrm{CH}_{2}-\mathrm{Si}_{\left(\mathrm{CH}_{3}\right)_{3}}
$$

The reactions of allylsilanes are very similar to the reactions of vinylsilanes. Allylsilanes undergo regiocontrolled electrophilic attack similar to vinylsilanes. Such a reaction has been utilized for the synthesis of commercially important monoterpenoids: artemisia ketone, ipsenol and ipsodienol.<smiles>CCC=C(C)C</smiles>

$\mathrm{Si}\left(\mathrm{CH}_{3}\right)_{3}$<smiles>C=C(Cl)C=C(C)C</smiles>

o an $\mathrm{AlCl}_{3}$

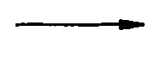

o

Artemesia ketone<smiles>C=CC(=C)C[AsH](C)C</smiles><smiles>C=CC(=C)CC(=O)CC(C)C</smiles>

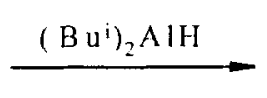<smiles>C=CC(=C)CC(O)CC(C)C</smiles> 


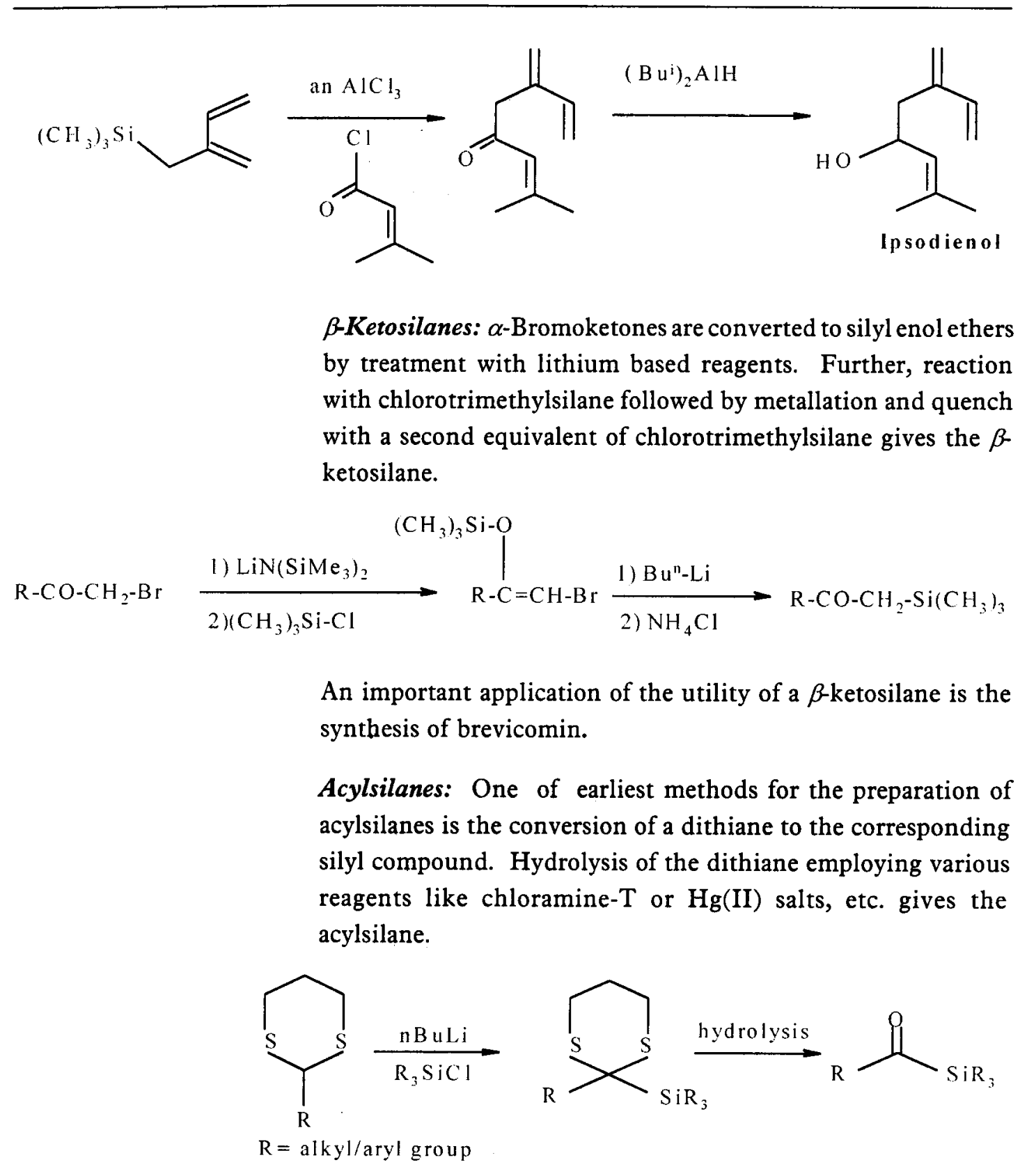

An instance for the utility of an acylsilane in natural product synthesis is the synthesis of the true pheromone component of sweet potato leaf folder moth. The Wittig reaction of an acyl silane with a phosphorous ylid forms a vinyl silane. Further desilylation and oxidation gives the pheromone. 


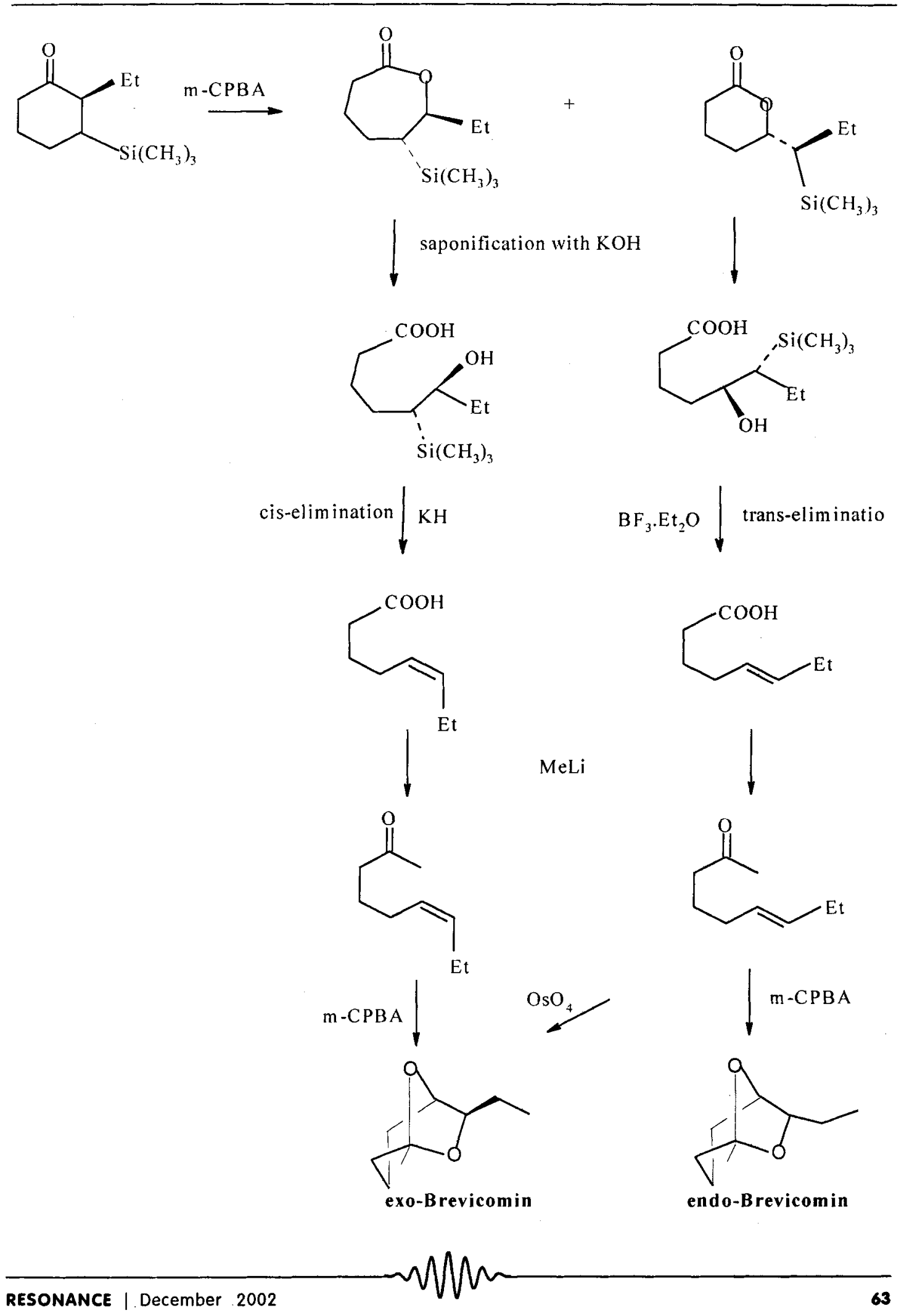


<smiles>CCCCC(=O)[SiH](C)C</smiles>

\section{Suggested Reading}

[1] J Clayden, N Greeves, S Warren and $P$ Wothers, Organic Chemistry, Oxford University Press, Oxford, pp. 1287-1304, 2001.

[2] S E Thomas, Organic Synthesis: The Roles of Boron and Silicon, Oxford University Press, Oxford, pp. 4791, 1994.

[3] E W Colvin, Silicon Reagents in Organic Synthesis, Academic Press Inc., San Diego, CA, 1988.

[4] WP Weber, Silicon Reagents for Organic Synthesis, Springer Verlag, Berlin, 1983.

Address for Correspondence 5 Hari Prasad Department of Chemistry Central College Campus Bangalore University Bangalore 560001 , India Email: hariprasad@mycatsindia.com

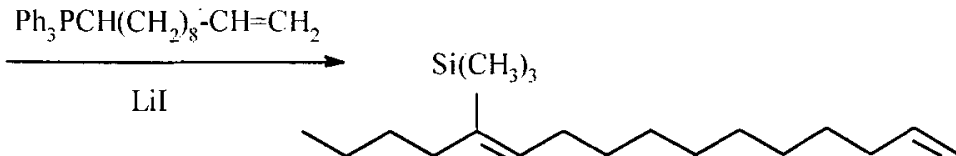<smiles>[Tl]C1CCCCC1</smiles><smiles>CCCCC=CCCCCCCCCCCC=COC(C)=O</smiles>

Sweet potato leaf folder moth pheromone

\section{Conclusions}

Illustrated in this article is a brief outline of organosilicon chemistry and the highlights of the utility of organosilicon compounds in natural product synthesis. Due to the high affinity of silicon towards oxygen, catenation as observed in carbon chemistry is absent in silicon chemistry in the oxygen rich surface of the earth. Life on earth is due to the formation of carbon compounds. These compounds provide a backbone for molecular components of living things. It is known for a long time that primitive plants and animals such as horsetails (Equisetum), diatoms and some sponges use silicates as part of their skeletal composition. Silicon is also required as silicates in trace quantities for the growth and reproduction - in higher animals. Whether other life forms in the universe possess silicon as a primary element for their structure growth and metabolism in atmospheres lacking in oxygen is still open to debate.

"Dedicated to Prof. G Nagendrappa on the occasion of his 60th birthday. The author thanks the UGC-COSIST for financial support. 